\title{
WOMEN IN SCIENCE
}

\author{
Deborah Powell \\ Executive Dean and Vice Chancellor for Clinical Affairs \\ University of Kansas School of Medicine
}

Women are a presence in science, certainly in the United States and in Europe. In 1994, 46\% of new U.S. doctoral degrees were awarded to women. Many national scientific societies are or recently have been headed by women and women are or recently have been directors or deputy directors of large federal science agencies including the Department of Health and Human Services, National Institutes for Health and the National Science Foundation. Women scientists are Presidents or Chancellors of major research universities. Minorities are still seriously under represented in many areas of science and in leadership positions but there are more minority males and females now in leadership positions in universities and in the federal government, including the U.S. Surgeon General, formerly the director of the Center for Disease Control.

Despite this obvious and dramatic difference over the past two decades there are significant problems for women and minorities in science. I'd like to touch on three areas in this brief talk:

- Mentoring

- Career Pathways and Obstacles

- Affirmative Action

\section{Mentoring}

Mentors are important in career development, and planning for young scientists. Role models in a somewhat different way help careers, often by example, with strategies for achieving a balance of professional and personal goals. Mentors and role models both are usually more senior individuals and until recently there was a distinct lack of senior women and minorities in science to serve these functions. Although non-minority men have served as successful mentors for young women and minorities for a long time, they are not as effective as role models. Also for many men, mentoring of younger male colleagues has been easier and more spontaneous. Often this has happened in informal settings-going out for a beer, playing sports. Even when senior women were available in academic departments or labs, they were often so busy balancing their own family and professional lives that they did not have time to spend with younger colleagues. (Also we should note, until recently there were very few senior women.) Consequences of this have been inequality of tenure awards to women and the more frequent finding of women in the junior academic ranks as well as non-tenure academic tracks. It has greatly helped to have more senior women to serve as mentors and role models in recent years. 
A number of societies including AWIS, AMWA, AAUW and many science specialty societies have recognized the importance of effective mentoring and have developed formal and informal mechanisms to facilitate this. Recently an email based mentoring program for female engineering and science students called Mentor Net began national pairing of undergraduate and graduate students with mentors working for a large number of companies with start-up funding from AT\&T and Intel. Mentor Net grew out of a 2 year pilot project for female engineering students at Dartmouth and this year plans to match 500 students from 25 schools with 500 mentors. It should be possible to develop similar university based programs on an institutional level or as a regional consortium.

\section{Career Pathways and Obstacles}

Family considerations impact the careers of both men and women; however women's careers are usually more directly influenced by decisions to marry and have children. Childbirth, pregnancy complications and breastfeeding are uniquely women's issues, and in many families responsibility for childcare falls to the woman. In some cultures, women's careers are regarded as secondary to those of men. Newly flexible promotion and tenure policies have helped young women and men establish their academic careers without having to postpone child rearing. However many women in both the past and present have interrupted their careers to produce and raise their children. Many of these women plan to re-enter the scientific workforce at some point, only to find a number of barriers to this re-entry. These include significant financial responsibilities, outdated knowledge and skills, and loss of networks.

Financially, not only are the increased expenses of returning to graduate school or training programs a cost, but also the older woman is often faced with mortgages, college expense for children, medical expenses for family or aging parents, etc. Likewise the reentering scientist may often have family concerns such as young children, older adolescent children, or aging parents which limit the choices and time that can be devoted to career rebuilding. Many women seeking to re-enter scientific fields find their knowledge is outdated as is their skill base. This problem is really unique to science and technology fields but may seem insurmountable without appropriate help. Networks of scientific colleagues established during graduate and postgraduate training often have disappeared by the time a woman decides to reactivate her career in science. These networks are critical for keeping current in one's area of science, for mentors and role models, and for career opportunities. Many professional societies and federal agencies such as ORWH and NIH have begun to offer support and training opportunities for reentry scientists. ORWH offers a fellowship program for fully trained re-entry men and women as a supplement to existing NIH grants. Clearly universities have a responsibility and opportunity in this arena as well. 


\section{Affirmative Action}

In a speech given to a national science foundation conference on Women in Science on December 14, 1995 (and in a subsequent essay written for Science Now in March 1996) Radcliffe College President Linda Wilson made the following comments. "The scientific enterprise cannot thrive in the future unless it is open to all segments of the population. The native intellectual capacity for significant and sustained contributions in science, math and engineering is present in all groups in the population: male and female; white, Native American, African-American, Asian American, Hispanic American; and across all socio-economic groups. Diversifying the pool of scientists, mathematicians and engineers is necessary to ensure excellence in these fields. Drawing only or primarily on a narrow segment of the population will inevitably diminish the capacity for excellence." She goes on to note that we will not meet our national goals unless we recognize the diversity of our human resources and unless we bring the diverse members of the population into full partnership. She states that "as a nation we have been squandering talent, partly through ignorance of its existence, but partly through reluctance to share power and responsibility. Affirmative Action is a necessary step and a fair step if implemented wisely." Other scientists have also recognized the dangers to science in current trends with Affirmative Action. In an editorial in the March 29, 1996 issue of Science, Dr. M.R.C. Greenwood, Dean of Graduate Studies and Vice Provost for Academic Outreach at the University of California-Davis and former Associate Director of Science in the Office of Science and Technology Policy writes: "This is a time of extraordinary paradox. Just as we begin to reap the benefits that diversification of the scientific leadership of the nation is bringing us, we are also faced with a new popular perception that the tools that helped to open our doors and our eyes were wrong, that they created 'preference' not 'equalizers.' Drawing more women and minorities into science is no longer so much about writing the wrongs of the past as it is about developing talent for the next century. Recent estimates indicate that between the mid-1980's and the year 2000 the majority of growth in the labor force will come from the entry of women, people of color and immigrants. In an international, stridently competitive 'information age' we have to mobilize all the latent talent in this new workforce. Scientific leaders from diverse backgrounds ... are desperately needed because their presence will help inspire others to follow their lead."

The recent challenges to affirmative action programs may indeed be as these women predict, detrimental to the progress made by women in their scientific careers and possibly even more devastating to the careers of minority scientists who have not yet reached sufficient numbers to form the important mentoring networks necessary for scientific success. We will lose so much if we do not actively encourage and support access and diversity. Young women and minorities, contemplating careers in science, must see others who will show them it is possible. It has been stated that women often experience the institutional climate of science as chilly because for women there is value in a balance between intellectual challenge and supportive relationships. For women, often, the community and environment in which they work is as important as the projects on which they work. This balance between career and community, may be what 
promotes women's creativity in science and makes all of us examine questions in different ways. To quote President Linda Wilson again "we now seem to have supply and demand imbalances for scientific personnel, but that is partly because we have had too narrow a view for the roles to be played by those trained in science. We need a more robust design." She ends with the following sentiment: "my view of the future is optimistic because I see the opportunities to restructure and reshape our expectations. I am utterly convinced that a key to advancing our society lies in advancing women. But I am also convinced that the path must involve concerted, sustained attention to the development of partnerships and deeper communication-between men and women; across boundaries of cultural, racial and socio-economic differences; across disciplines and institutions; and among the sectors of our society. We need to bridge the gaps between scholars and educators, policy makers, the media, the business community, grass root organizations, and the public at large."

In summary, women are an extremely valuable resource in science. Programs that have been put in place over the last decades have been effective in moving women into senior levels of scientific careers were they can serve as effective mentors and role models for younger women coming up the ranks. They have also moved women to the forefront of discussions about science on a national and institutional level. Although advances have been made in a similar vein for minorities the progress has not been as great. Because science, especially biotechnology, biomedical science, engineering, mathematics, is so important to the future economy of this country we cannot afford to disenfranchise any of the creative minds of the next generation. Women still face difficult choices between having a family and building a career, and advances are still threatened by the potential loss of important support programs including Affirmative Action. It is incumbent on all us within the universities to recognize both how far we have come and how far we need still to go. 